\title{
"HACIENDO RELACIÓN DE LAS COSAS TOCANTES A SU GOBIERNO". EL ORDEN DEL INCA EN LA DOCUMENTACIÓN COLONIAL TEMPRANA (PERÚ,1540-1570)*
}

\author{
“HACIENDO RELACIÓN DE LAS COSAS TOCANTES A SU GOBIERNO”. \\ THE INCA ORDER IN EARLY COLONIAL DOCUMENTATION \\ (PERU, 1540-1570)
}

Germán Morong Reyes**

\begin{abstract}
Durante los cuarenta años que siguen a la conquista del Perú, la alusión positiva a los mecanismos e instituciones incaicas de autoridad, figuró con frecuencia y con cierta sistematicidad en la documentación colonial referida a materias indígenas; tributación, trabajo, policía, evangelización y buen gobierno. Estas informaciones -sobre la base de la experiencia in situ-, en manos de clérigos y funcionarios reales, obedecieron en principio a una preocupación claramente etnográfica e informativa. Luego, llegaron a tornarse esenciales en virtud de proponer emular los dispositivos de control que habían garantizado una obediencia irrestricta de parte de las sociedades andinas a un régimen considerado tiránico pero eficiente a nivel gubernamental. Paralelamente a la cronística temprana-fabricada como historia y con un carácter apologético-, relaciones, cartas, memoriales e informes, fungieron de escrituras oficiales al servicio del colonialismo, al reiterar diacrónicamente la necesidad de restituir un régimen que había mantenido a los indios totalmente sujetos y en su máxima entrega laboral. El objetivo de esta contribución es analizar este tipo de textos como un corpus general que, a nivel comparativo, permite ponderar la circulación de un saber específico que progresivamente fue usado e instrumentalizado por religiosos, oidores y virreyes, tanto para denunciar el mal gobierno colonial, como la progresiva disipación de los naturales tras la llegada de las huestes hispanas en 1532 .
\end{abstract}

Palabras claves: Informaciones, Incas, sujeción colonial, Perú colonial, siglo XVI.

During the forty years after the conquest of Peru, the positive allusions on Inca mechanisms and institutions were frequently and with a certain systematicity present in the colonial documents related to indigenous matters; taxation, labor and good government. These information -based on the experience in situ-in hands of clergymen and royal public servants, were dued to ethnographic and informative concerns, later on they became vital in order to propose to emulate the control mechanisms which had allowed the unrestricted obedience of the Andean communities to a regime considered tyrannical, but efficient on a governmental level. At the same time the early chronicle works -written as history and with an apologetic character-reports, memorials, informs acted as official writings at the service of colonialism, as they reaffirmed diachronically the necessity of restitution of a regime that had kept the Indians completely subject and on their highest working level. The objective of this contribution is to analyze this type of text as a general corpus which, on a comparative level, allows to weigh the circulation of a specific knowledge that was used and exploited progressively by clergymen, judges and viceroys, as much to report the bad colonial government as the progressive disappearance of the natives after the arrival of the Spanish armies in 1532.

Key words: Informations, Incas, colonial subjection, colonial Peru, XVI Century.

\section{Introducción}

Durante los cuarenta años que siguen a la conquista del Perú, a partir de 1532, los españoles mostraron una habilidad excepcional para detectar y acopiar con fecunda sistematicidad información acerca del funcionamiento del poder político en los Andes prehispánicos (Gibson 1948; Lohmann 1957; Wedin 1966; Zavala 1976; Rostworowski 1983; Stern 1986; Pease 1992; Martínez 1995;
Zuidema 2008; Zuloaga 2012, entre otros). Más allá de la complejidad inherente que imponen este tipo de descripciones, al querer traducir experiencias políticas y de gobierno ajenas, con un grado de particularidad realmente excepcional, estas muestran la necesidad del poder colonial de ubicar a los exponentes locales e imperiales de autoridad-curacas e inca- en un grado de legibilidad suficiente como para organizar e imponer el sistema de encomiendas primero (1532-1550) y los intentos de gobernar el

\footnotetext{
* El presente artículo es resultado del proyecto FONDECYT de iniciación $\mathrm{N}^{\circ} 11180045$, del que el autor es investigador responsable, ANID-CHILE.

** Centro de Estudios Históricos, Universidad Bernardo O’Higgins. Santiago, Chile. Correo electrónico: german.morong@ubo.cl
} 
virreinato más tarde (1550-1580) (Zuloaga 2012; Presta 2014; Penry 2019). No obstante, esta organización categorial, con referentes clásicos en términos políticos (Julien 2000; MacCormack 2007), se llevó rápida, sistemática y desordenadamente entre voces discordantes y expresó una inestabilidad conceptual al momento de aplicar tales categorías (señores, príncipes, principalejos, tiranos, reyes, señor principal, etc.) que parcialmente fue resuelta a medida que la experiencia generó informaciones más prolijas, producto de la proximidad de sus redactores con las sociedades andinas.

Esta práctica escritural de profuso acopio, caracterizó e inauguró también una producción documental que incluyó géneros diversos, como fue el caso de la cronística andina y la serie de tratados, cartas, relaciones, memoriales, pareceres, informes, provisiones y cédulas. Este segundo grupo de textos es constitutivo de una unidad en la medida en que algunos de ellos cumplieron un rol específico en la administración colonial, informando acerca de lo que la Corona solicitaba y abriendo un flanco indagatorio con fines de incidir efectivamente en las decisiones eventuales que la autoridad llevaría a cabo, en el contexto de la comunicación oficial entre esta y las Indias (Gaudin 2017; Brendecke 2012).

Mediante estos discursos, de múltiples actores y "voces", en un contexto histórico específico, que fueron creando su objeto y formalizando sus propias reglas de referencia y traducción, acerca de la experiencia de lo "visto", es que los españoles explicaron el imperio incaico no solo para alabar su alta y coactiva eficiencia productiva (en un periodo crítico para la hacienda real), sino también la necesidad de restituir parte de sus "leyes" y disposiciones orientadas al buen gobierno de sus vasallos ${ }^{1}$. Por su parte, algunos curacas -tornados en alcaldes de indios-, por medio de las acomodaciones que impuso la traducción dominica de los frailes, lamentaron la ausencia de sus antiguos reyes incas al ver que el régimen colonial los pervertía moralmente. Considerando la situación política del centro sur andino, entre 1532 y 1570 , esta circulación fragmentaria constituye un espacio privilegiado para analizar la construcción de los "saberes" coloniales en un ámbito de discusión gubernamental y en un contexto de legitimidad progresiva de la cultura del conocimiento empírico moderno (Barrera-Osorio 2006), con el que se pensó la diferencia y se tejió la legitimidad del dominio.
Asumimos aquí las perspectivas analíticas de un conjunto reciente de investigaciones (Mumford 2011 y 2012; Lamana 2012; Zuloaga 2012) y no tan recientes (Gibson 1948; Lohmann 1957; Brading 1991, entre otros) que sostienen que la descripción política de los incas y la construcción fiscal de los indios dio cuenta de un derrotero de urgencia gubernamental, que progresivamente conllevó al interés etnográfico por los mecanismos de dominio prehispánicos -el inca y los curacas-y su eventual restitución negociada al servicio del colonialismo y los intereses locales de élites indígenas. Este interés, redundó en los intentos de adecuar las instituciones coloniales -mediante distintos niveles de mediacióna la experiencia sociopolítica andina, heredera de modos de producción y gobierno suficientemente exitosos como para ser desplazados en el corto plazo. Estas afirmaciones se encuentran ya sugeridas en las obras de Charles Gibson y Guillermo Lohmann que, instalados en una historiografía dialogante con el desarrollo vertiginoso de la etnohistoria andina, a mediados del siglo pasado, desarrollaron explicaciones respecto de las necesidades peninsulares de adecuación colonial al "gobierno del ynga", poniendo énfasis en la organización incaica de poder a escala local. Lohmann (1957: 7-11) explicaba cómo los españoles miraron asombrados la existencia de una organización decimal provista de autoridades intermedias eficaces en el control de la población. Por su parte, Gibson (1947: 14) mostró con elocuencia que "ciertas fases del dominio español fueron guiadas por la imitación deliberada de las prácticas incaicas precedentes" 2 .

Esta adecuación debía ser coherente también con el respeto a los fueros y costumbres de las comunidades anexadas a la Corona, siguiendo una tradición de prácticas jurisdiccionales previas (Góngora 1951). En el caso de México, las leyes Nuevas de 1542 contenían ordenanzas destinadas a mandar que los indios fueran juzgados conforme con "sus costumbres"3 (Saravia Viejo 1978: 27). En el Perú, la discusión por esta recomendación tiene en el licenciado Polo Ondegardo al más conocido exponente.

Mi interés, en esta contribución, valiéndome de fragmentos textuales de un conjunto específico de documentos al servicio del buen gobierno imperial, producidos entre 1540 y 1570 por autoridades, funcionarios, clérigos, entre otros ${ }^{4}$, intenta retomar el ámbito de la gobernabilidad colonial, documentando parte de los derroteros ideológicos 
y prácticos de su ejecución. Asumimos que el trayecto de esta producción escritural -desde 1540 aproximadamente- caracteriza un largo periplo en que la desestabilización constante de la política colonial (guerras civiles, levantamientos antifiscales y cuestionamiento de la legitimidad de la conquista del Perú) y la controversia por el trato y sujeción de los naturales (con fines a su "aprovechamiento" y siempre respetando teóricamente su "libertad"), además de la polémica por la perpetuidad de las encomiendas (con clara intervención de dominicos lascasianos y letrados proclives a la Corona), favoreció una discusión pertinente a la legitimidad y efectividad del inca como de sus autoridades intermedias. Todo ello, en virtud, sobre todo, de la efectiva exacción fiscal que lograron del trabajo de los naturales -erradicando el ocio- (Zuloaga 2012: 117-138; Mumford 2011) y del conocimiento que lograron de las poblaciones y sus "calidades" (adecuadas a "temples" específicos). También de la flexibilidad de su sistema tributario, atendiendo a la diversidad ecológica y su incidencia en el potencial productivo de los naturales. Este buen gobierno, normado y justo, también fue excesivamente autoritario y, en contextos discursivos e instrumentales específicos, asumió la forma de una cruel tiranía, tan cara a las discusiones peninsulares de legitimidad política y social.

En segundo lugar, para clérigos y funcionarios la eficacia de este temido poder siguió también la vía de una explicación ontológica y antropológica derivada de la empiria. Para muchos letrados, utilizando a conveniencia el marco aristotélico de la servidumbre natural (Pagden 1988), los indios poseían una calidad inherente, fija y no cambiante (Lamana 2012), tendiente al ocio, la embriaguez, la timidez -producto de una complexión flemática y melancólica-, además de todo tipo de "vicios" (Earle 2012; Morong 2014, 2016 y Morong y Brangier 2019). El conocimiento de esta "calidad", que los españoles identificaron en términos teológicos y jurídicos como condición de rusticidad, miserabilidad, incapacidad relativa y minoría de edad (Cunill 2013) ${ }^{5}$, con una "evidente" falta de razón, prudencia y virtud, legitimó la restricción de la libertad natural favoreciendo la imposición de una cruel pero necesaria tiranía prehispánica. Este mismo razonamiento permitió, a la postre, la separación discursiva de dos categorías elementales; mientras que indio fue un homólogo de la servidumbre, la inferioridad inherente y el trabajo reglamentado -en tanto categoría fiscal-, la noción de inca aludió a una categoría política equivalente a la monarquía o a la tiranía, observada con muy buenos ojos en un contexto de crisis. Constitutiva con el tiempo de una idealización utópica, construida para denotar un orden político justo, ordenado y eficiente, con prácticas orientadas al paternalismo y al colectivismo (Parra 2015).

A mediados del siglo XVI, virreyes, oficiales y clérigos (pero también mercaderes e indios) utilizarán reiteradamente los enunciados "en el tiempo del inca", "orden del inca" o las "leyes del inca" para referir tanto un excesivo poder autoritario como a buenas y necesarias prácticas gubernamentales. Atendiendo a las propuestas analíticas de Gonzalo Lamana (2012: 52-53), derivadas de su análisis a los informes de Polo Ondegardo (1561 y 1571), entendemos estos discursos -en un contexto histórico, jurídico y político- como expresión de la tarea que enfrentaron los pensadores colonialistas al producir una explicación esencialista del orden de las cosas que reasegurase la inferioridad de los indios, privándolos de pensamiento político y libertad.

Con todo, el objetivo de esta contribución analiza un conjunto específico de textos como un corpus general que, a nivel comparativo, permite ponderar la circulación de un saber específico que progresivamente fue usado e instrumentalizado tanto para denunciar el mal gobierno colonial, como la progresiva disipación de los naturales tras la llegada de las huestes hispanas en 1532. A nivel metodológico, hemos seleccionado fragmentos textuales al interior de un universo tipológico que engloba a relaciones, memoriales, cartas, informaciones, pleitos y tratados ${ }^{6}$. Estos textos "oficiales", producidos in situ, permitieron el desarrollo sistemático de una vinculación clave recientemente estudiada con fruición: la emergencia de la cultura del conocimiento empírico moderno con prácticas de dominio y administración (Barrera-Osorio 2006; Brendecke 2012). No hemos incluido aquí el corpus de la cronística de interés indígena, simplemente porque aquella ha sido suficientemente estudiada desde perspectivas variadas.

\section{De la indagación a la definición del buen gobierno; los incas en las primeras relaciones y memoriales}

Las primeras informaciones de los incas ${ }^{7}$, mayormente vinculadas al gobierno del licenciado 
Cristóbal Vaca de Castro (1541-1544), expresan la necesidad de ordenar el tributo en los Andes, en medio de una ardua discusión acerca de su imposición y tasación (Zavala 1976). La dirección indagatoria, ponderando el sistema de tributación prehispánico y comparando su exigencia con el colonial, puso a los incas como objeto de discusión político-administrativo.

Entre 1539 y 1558 , tres textos que fungieron de cartas y relaciones constituyeron, junto con las crónicas de Pedro Cieza de León y Juan de Betanzos, los primeros relatos precisos referentes al gobierno de los incas (Pease 1995). Probablemente, entre 1539 y 1541 fue escrita la Carta sobre el gobierno, las costumbres y los antiguos ritos del Perú ${ }^{8}$. Se trata de un texto breve, editado tres veces en el siglo XX (Trimborn 1934, Rowe 1966 y Gentile 2013) y valorado etnológicamente por ser el primer informe escrito del gobierno de los incas. Su autor anónimo", quien nominó a su escrito como "memorial", pudo haber sido un capellán que declaró que sus informaciones orales derivaban de lo que escuchó de los indios, lo que supone que fuese un párroco que vivió entre aquellos. El tema central del texto versa sobre la manera en que los incas organizaron el territorio que gobernaron (Julien 2016a: 17071708). Siguiendo a su autor, los incas cometieron actos tiránicos al principio de su mandato, pero su interés esencial al momento de dominar otras provincias fue crear y establecer instituciones religiosas y racionalizar la organización local.

La descripción del memorial -en el marco de esta argumentación- pone en evidencia, para una fecha temprana, anterior a las guerras civiles (1544-1548), tres tópicos centrales; autoritarismo y eficiente organización política (“orden” en policía), conocimiento de las distintas comunidades y ajuste tributario a base de ese conocimiento y tratamiento biopolítico, exitoso al mantener una alta densidad poblacional en tanto potencial productivo. Al igual que los relatos cronísticos, la obertura del texto presenta a los incas como agentes civilizadores en el valle del Cusco, exigiendo casi perplejo a su destinatario que "entienda la poliçia que vna jente tan barbara alcanço en hasta diez señores que dizen que rreynaron dellos sin tener letras diuinas ni vmanas ni lunbre de otros antepasados" (Anónimo RBME, Fol. 457r en Gentile 2013: 515). El dominio sobre las comunidades sujetadas siguió "principios" que fueron "por via de amistades y confederaçiones con sus vezinos $[\ldots]$ y avn despues quando pudieron llevaron esta via todas las vezes que hallavan oportunidad //" (fol. 457r).

Además de sostener que la política de expansión de los incas consideró mecanismos flexibles de dominio, el capellán anónimo explica, siguiendo un razonamiento alojado en el principio de legitimidad del poder soberano frente a la comunidad gobernada (contratus subjetionis), que antes de "señorearse" los incas hacían entender a sus contrarios "que se movian por su bien dellos / para darles mas politica via de biuir y darles dios a quien sirviesen" (fol. 457r).

Admirado por el poder de esta forma de control político, es uno de los primeros relatos que traduce al lector español la función del tocuirico (túcuyricoc), que no debe confundirse con el tocricoc (Ttocricuk) (Ossio 2008). En diversas fuentes, el tocuirico, "el que todo lo mira" figura como un cargo local de administración imperial, confundido con el rol de los corregidores y oidores, destinados por el inca a vigilar y hacer cumplir las leyes. Para el autor de este documento, sobre el cacique de guaranga;

"ponia el inga vn / orejon cavallero de su casa de quien muncho se fiava que era como vedor que en su lengua se llama vn / tucuyrico / que quiere dezir todo lo mira /. a este tenian gran rrespeto tenia por si criados de confiança para avisar al inga de todas las cosas que a la governaçion convenían" (fol. 457v).

El énfasis puesto en el control de las poblaciones sujetadas cobró relevancia, a ojos hispanos, en el sentido de que un dominio tan extenso necesitaba de este cargo sobre todo para vigilar y controlar la eventual disidencia local o provincial (Anónimo RBME, Fol. 458r en Gentile 2013: 516). Paralelamente, la descripción de las instituciones menciona al Chasqui (Cachac) como correos humanos cuyas medidas de trabajo diario se organizaban en postas o tambos. El autor señala que los incas "para saber con gran breuedad todo lo que se hazia en cada parte y provinçia de sus rreynos vsaron a tener postas que en su lengua se llaman / chasquis [...] para que corriesen de noche y de dia los avisos que venian al inga" (fol. 458v). La importancia de estas dos figuras administrativas se vuelve doblemente relevante, si atendemos a la fecha especulada del documento (1539-1541); por un lado, serán estos dos cargos incas en los que luego la documentación generada por cronistas, letrados y funcionarios, entre 1540 
y 1580, pondrá atención exhaustiva como ejemplo de control y eficiencia gubernamental (como puede comprobarse en cartas, relaciones y tratados entre 1560 y 1570) y, por otro lado, la descripción de este cargo viene acompañada por quizás la más temprana y escueta sugerencia restitutiva, ya usada por Gonzalo Pizarro; "Mas dado caso que agora conviniese que las cartas de la governaçion se despachasen por esta manera menos pesadumbre es para los indios" (fol. $458 \mathrm{v}$ ). De forma más extensa podremos encontrar esta misma exigencia en la Relación de Hernando de Santillán (1563) y en el tratado capital de Juan de Matienzo (1567), años más tarde.

De la mano con la cita anterior, otras cualidades percibidas por nuestro autor anónimo se vinculan al flexible sistema tributario y al conocimiento de las calidades de los sujetos y del territorio -en un Perú diverso y contrastante- para el cumplimiento de aquella exacción. Una de las críticas posteriores, efectuadas sistemáticamente por el clero regular y los procuradores de indios, fue que los encomenderos y el gobierno colonial, a contrapelo del incaico, movilizaba poblaciones de un temple a otro (asumiendo la variedad climática del Perú de costa a cordillera) sin considerar el perjuicio de la salud de los naturales, de distintas "calidades", habituados a temples específicos (costa, sierra, montaña, altiplano y selva ${ }^{10}$. Esta materia fue objeto de larga discusión y de normatividad por parte de las autoridades coloniales por incidir en el descenso demográfico de los naturales, a partir de la implantación de la encomienda y la legitimidad arbitraria que fue cobrando el servicio personal. El autor del memorial señala que cuando se descubrían minas y se necesitaba de mano de obra para su explotación "mandava el inga mirar que tenple de tierra era y de otra provinçia que fuese de aquel tenple sacava el multiplico de los hunos y guarangas / y poblavan alli y despues de poblados sacavan la plata o el oro" / y si los cristianos guardaran este modo no se destruyera la tierra / que dado que aya lugar que se ayan de seguro minas /." (fol. 458v)". La adecuación de las poblaciones compelidas a los temples, "mirar que tenple de tierra era" para la ejecución del tributo, es presentada en el documento como una segunda recomendación restitutiva para "conservar la tierra".

Esta misma argumentación es presentada, años más tarde, en La Relación, Conquista y Población del Pirú, Fundación de algunos pueblos (Segovia 2019 [1552-1556]: 113-217) ${ }^{11}$, texto últimamente atribuido al clérigo presbítero Bartolomé de Segovia (Roselló 2019: 11-48; Julien 2016b, tomo III: $1718)^{12}$. El texto de Segovia agudiza la terrible y caótica descripción de la explotación colonial sobre los naturales, observando con pavor el sistemático desmoronamiento de las instituciones prehispánicas frente al propio deterioro de la empresa de conquista castellana. Su relato, siguiendo un estilo retórico similar al memorial anónimo, describe por medio de la observación in situ una organización política andina ya establecida en un marco de exigencia moral, denunciando un contexto inmediato que necesitaba reordenamiento (Roselló 2019: 50). Tras describir de modo escueto la organización incaica otorga una descripción de la adecuación de tributo justo en función del bien común. En esta descripción, el inca "no consentía haber ningún indio pobre ni menesteroso, porque había orden [...] $\sin$ que el pueblo recibiera vejación ni molestia, porque el inca lo suplía de sus tributos, no se movían los naturales a andarse de unas partes a otras" (Segovia 2019 [1552-1556]: 158). Con rígida autoridad y con piedad cristiana los incas, mediante un orden encuadrado en las necesidades de sus sujetados, habían impedido la pobreza aplicando el tributo sin perjuicio alguno del bien común.

A partir de 1551, y producto del impacto ocasionado por los infructuosos intentos de frenar el abusivo y oneroso régimen de encomiendas y normar el tributo, las audiencias americanas debieron elaborar informes de "los señores que había, tributos que pagaban los naturales en la gentilidad" (Esteve Barba 1968: XXV) con el objetivo de "conocer las características del sistema tributario prehispánico y los cambios acaecidos por la introducción del sistema colonial de encomiendas y repartimientos" (Honores 2004). Esta solicitud, emanada de una cédula real de 1553 y luego de otra de 1559 (Santillán 1968 [1563]: 138; Ortiz de Zúñiga 1962 [1562]: 9), condujo a una sistemática práctica de acercamiento con las comunidades andinas por medio de elaborados interrogatorios. En 1555 Carlos V envió dos instrucciones específicas al marqués de Cañete (Hanke 1978-1980: I, 43-51), ordenándole un sistema de tasación del tributo indígena para las encomiendas, el nombramiento de alcaldes de indios (para administrar justicia) y visitas a la tierra con el fin de recabar información in situ y ponderar la capacidad tributaria por comunidad. En 1557, y siguiendo estas instrucciones, el licenciado Damián de la Bandera, experto conocedor de la sociedad 
andina (Honores 2016: 1) siendo justicia mayor de la ciudad de Huamanga, redactaba su famosa "Relación general de la disposición y calidad de la provincia de Guamanga, llamada San Joan de la Frontera y de la vivienda y costumbres de los naturales della" (De la Bandera 1881 [1557]: 96-103). En esta, indagando a fondo sobre la antigua provincia de Vilcashuaman, pudo conocer el funcionamiento del poder a escala local, poniendo atención a la "gobernación del inga" (De la Bandera 1881 [1557]: 98).

Al igual que el memorial de 1539-1541, analizado más arriba, el interés está puesto en la organización sociopolítica estructurada en unidades decimales (guarangas, pachacas, hunos), con autoridades que controlaban desde diez mil a cinco individuos, "y desta manera era muy fácil la gobernación" (98-99). En este ordenado control, asimismo, reaparece la figura del tocuirico; "Sobre cada provincia habia un gobernador y éste era un capitan del Inga, al cual llamaban tucuyrico [tucuiricuc], que quiere decir, todo lo mira [...] conocia de cualesquier causas y podia castigar y matar al que lo merecia.'(99). Según De la Bandera este cargo, castigador y disciplinador, conocía de los "negocios civiles" y procuraba en las comunidades gobernadas que no hubiese ningún tipo de discordia (99-100). El inca, tres veces al año enviaba a sus visitadores para "ver qué cuenta y razon habia en todo", "deshacer agravios" y evaluar el desempeño de los tocuiricuc. El lamento del licenciado, siguiendo esta argumentación, es observar que la principal causa de la tiranía colonial de los caciques, sobre sus ayllus y parcialidades, está asociada a la ausencia de un poder central;

"con la entrada de los españoles y falta de gobierno del Inga, se alzaron con todas aquellas cosas y preminencias que eran del Inga y con la jurisdicción civil y criminal que no tenian, y cada uno en su muladar quedó hecho lo que era el Inga en todo el reino" (99).

La emergencia colonial del poder de los curacas, situación latamente estudiada en las últimas cuatro décadas (Spalding 1984; Stern 1986; Pease 1992; Zuloaga 2012), es vista por el licenciado como una tiranía insoportable sobre las comunidades tributarias, sin orden ni justicia (elemento medular en la prosa de la cultura letrada de funcionarios proclives, tanto a la encomienda como al corregidor de indios, en las décadas de 1556-1570). Los indios, hasta aquí, son víctimas silentes del juego de poderes locales, objeto del duro proceso de reacomodación colonial de sus estructuras de poder previas en manos de autoridades étnicas, con nuevos poderes ajustados al contexto de un sistemático reemplazo de instituciones y agentes sobre las que depositar el tributo y la fuerza laboral. $\mathrm{Al}$ igual que el memorial anónimo y la relación de Molina/Segovia, otra de las descripciones positivas de la Relación de Guamanga está determinada por la flexibilidad y justicia de su sistema tributario;

\begin{abstract}
"Una de las principales causas porque los indios alaban la gobernacion del Inga y los españoles que alcanzaron á entender algo della lo sienten así, es porque todas estas cosas y otras muchas que se les ofrecian, las determinaban sin hacerles costas ni llevarles más tributos que el que daban al Inga [...] El tributo que daban al Inga en todo el reino (a), en todos los pueblos le hacian chácaras conforme á la calidad del pueblo y cantidad de indios" (De la Bandera 1881 [1557]: 102).
\end{abstract}

Hacia 1560 la documentación producida por religiosos o funcionarios, por requerimiento real memoria/relaciones, referida a los incas y a materias indígenas, pone en evidencia a lo menos cuatro prácticas interrelacionadas: el carácter autoritario de la "policía" incaica, su estricta y eficaz organización sociopolítica (precisa a escala local), su justa flexibilidad en el orden tributario, el conocimiento de las comunidades y los territorios y el respeto a esa vinculación determinista. No es posible sostener que estos textos, a pesar de denunciar el aspecto cruel y violento de la "policía" incaica, imputen a aquellos un régimen tiránico de forma explícita, como lo harán Matienzo, Sarmiento de Gamboa o García de Toledo, años más tarde (Duviols 1982; Mumford 2011; Millones 1998).

\section{El orden del inca y la condición colonial de los indios; del conocimiento etnográfico a la necesidad de emular}

Entre 1560 y 1570 la anhelada estabilidad colonial se sigue viendo entorpecida por varios factores inquietantes. Entre estos; la pertinaz controversia sobre la perpetuidad de las encomiendas y la discusión referida a la potestad jurídica y tributaria sobre los 
naturales, bajo el supuesto aceptado de la libertad de aquellos (Lohmann 1966; Pérez Fernández 1988). Asimismo, puede constatarse un estrecho correlato entre la disipación de los indios, la necesidad de mano de obra para alimentar la pujante minería de plata (Stern 1986, Assadourian 1982 y 1994 ), la corrupción intestina de los distintos poderes locales en desmedro del bien común y la omisión a provisiones, ordenanzas e instrucciones reales. La alusión al estado de la tierra, su perdición e improductividad, se vuelve un enunciado común para denunciar el comportamiento de funcionarios, religiosos, curacas, negros, mestizos e indios ladinos. Para las autoridades virreinales y para letrados como Hernando de Santillán, Polo Ondegardo y Juan de Matienzo, el orden colonial, traducido en mal gobierno -caracterizado por el turbulento interín que va desde 1544 a 1560-, había generado consecuencias irreversibles en los indios, sus comunidades y sus dirigentes (Lamana 2012). La disipación, la borrachera, el ocio, la holgazanería, el amancebamiento, la corrupción de la institución curacal, la mercantilización y occidentalización de yanaconas, constituían prácticas coloniales de asimilación ponderadas como nefastas (Stern 1986). En este sentido, la denuncia sistemática al estado de la tierra vendrá en muchos casos acompañada por una descripción positiva de los incas, incluso esta conducirá a una reflexión y posterior aplicación sobre la necesidad colonial de ese orden (Lohmann 1957: Brading 1991 Lamana 2012, Mumford 2012).

Una carta enviada al rey en 1562 por el mercader Juan Griego, famoso por ser pionero del tráfico textil entre Quito y Potosí (Salomon 1997: 40), permite poner en evidencia las afirmaciones precedentes. Al comentar la necesidad de audiencias para el buen gobierno, sostiene que estas permitirán;

"que vuestros vasallos y los naturales dellos alcançasen justicia con rrectitud y brebedad y pocos gastos-guaynacapaq y sus antepasados siendo barbaros debaxo de rrazon natural governaron sus tierras en justicia porque de sus súbditos heran temidos y obedecidos y no rrespetaban a personas y con su buen gobierno y de sus ministros sin leyes y sin letrados y procuradores y escrivanos poseia cada uno lo que tenia En paz de tal manera que ninguno osava matar ni hurtar ny mentir ni tomar a la mujer de otro ny perjurarse ni tomar tierra de otro cada uno [...] y no andavan los yndios e yndias vagamundos como agora andan y con nuestro exsenplo an perdido todo lo bueno y an aprendido todo lo malo y el que mas puede [ilegible] lleba la hacienda del otro $[\ldots]$ y tienen destruydo el rreyno los letrados y procuradores y si ay mil hombres rricos ay quince mill pobres los que tienen yndios y rrentas no se pueden sustentar ni tratar pleytos con exsesivas costas la tierra va cada dia en diminución y pobreza" (AGI, Lima 121, fol. 1r.).

El relato contiene un lamentable diagnóstico que, aludiendo al ineficaz y poco justo orden letrado colonial, sostiene que los incas a pesar de ser "barbaros debaxo de rrazon natural governaron sus tierras en justicia" (fol. 1r) dando a cada uno lo que merecía (enunciado central del buen gobierno). $\mathrm{La}$ percepción de un mercader español con experiencia en los asuntos indianos muestra que los indios "an perdido todo lo bueno y an aprendido todo lo malo" lanzados al hurto y la ociosidad, flagelados por la pobreza y la desidia, percibiendo que "la tierra va cada dia diminución y pobreza".

Siguiendo este razonamiento, advertimos en una carta fechada en enero de 1566 y rubricada por los alcaldes de indios de la parcialidad de Hurin Guanca del valle de Xauxa, una descripción elocuente (claramente en su redacción vemos la mano de los testigos de fe, un grupo de frailes dominicos) (AGI, Lima 121, fol. 60v) que nos permite la comparación con la cita anterior. Lamentando que en treinta años de dominio la Corona y sus gobernadores no ha procurado "en favorecer a los naturales desta tierra y en dar orden y concierto como dexen su barbaro modo de bibir" por ello "como gente dexada" ha prevalecido sobre estos "la soltura", concluyendo que "he tanto que avemos biendo tanto desorden en nuestro bibir que por ello estamos muy avergonzados" (AGI, Lima 121, fol. 59r). La supuesta declaración de los naturales, traducida a un locus religioso, termina por afirmar que los "yngas aunque carescieron de la luz de la berdadera rreligion y se bibia y bibio con toda orden y concierto y fuera de los bicios que agora abundan en que nosotros abiendo de ser lo contrario" (fol. 59r). Finalmente un mes después, en febrero de 1566, el capellán Cristóbal de Montalbo escribe al rey lamentándose del estado religioso de los reinos del Perú, de la licencia y liviandad con que los naturales se bautizan, instrumentalizando 
el sacramento para fines seculares. Advierte que "con hallar en estos Reinos la policía en que estos barvaros estavan puestos por sus yngas de no tiranizar ni hazer pecados abominables y no hurtar ni osar mentir ase pervertido tanto esta policía" (AGI, Lima 121, s/f) constatando que los caciques han instalado una tiranía sin provecho para los naturales. Reconoce la sensatez del licenciado Vaca de Castro en considerar la experiencia política previa "por que entendio que aquello convenia tener y guardar como cosa bien proveida y hordenada" (AGI, Lima 121, s/f).

La disipación de los naturales, argumento para condenar el mal gobierno colonial, comienza a generar, en virreyes y licenciados, una discusión que transita entre argumentos pragmáticos y ontológicos, combinando el conocimiento derivado de la empiria con categorías jurídico-teológicas enquistadas en la apreciación de la alteridad. Estas categorías esencialistas rondan permanentemente la escritura política de aquellos para argumentar sobre la necesidad de restituir un orden policial perdido. Bajo la anuencia de encomenderos, frailes y oficiales, las comunidades andinas han quedado libradas a su suerte y la firme moral anterior, sustentada en el miedo, ha dejado de existir.

En cartas dirigidas al monarca en 1562, el virrey Conde de Nieva señalaba que los indios "destas partes son tan groseros que ninguna cosa buena saben hacer" (Levillier 1921, Tomo I: 394) y consideraba que era tal su indolencia que no sabían prever y tomar conciencia de sus propias circunstancias existenciales, describiéndolos "como niños que no tienen prudencia para rregirse" o como "tan yncapazes y tan sin ser que no tienen voluntad de querer ni no querer" (Levillier 1921, Tomo I: 415416), concluyendo taxativamenteque que "vna de las cosas que mas a destruido y acauado esta gente es tener ellos liuertad". Esta naturaleza inherente, que de forma atávica gobernaba la conducta de los indios y que les impedía disfrutar de su libertad, había condicionado un régimen plagado de autoridades directas;

"pero por su inbescelidad y poca capacidad y entendimiento como lo son por la mayor parte en general de muchos tiempos atrás desde que los yngas gouernaron se saue siempre fueron governados por personas diputados y nonbrados asi para el buen gouierno como para que labrasen y cultiuasen la tierra sin tener ellos por si ninguna manera de gouierno ni otro ser ni voluntad ny sauer lo que auia de hazer mañana" (Levillier 1921, Tomo I: 444) ${ }^{13}$.

Esa falta de capacidad, entendimiento y policía en los indios había obligado a sus autoridades directas a negarles hacienda propia y sostener que "los yngas no menos eran señores de las personas" (Levillier 1921, Tomo I: 433), enajenando sus bienes y aplicando un férreo control sobre la fuerza laboral, con el fin de "tenellos mas subjetos y para hazelles trabajar labrar y cultivar la tierra" (p. 434). Para el virrey era necesario "entender y saver el servicio y subjecion grande que los yndios tuvieron" (p. 434). Con el tiempo las averiguaciones permitieron la comparación entre la encomienda-de exigencia desproporcionada- con el sistema laboral prehispánico, ya que a pesar de que en la época del inca se trabajaba con "gran servidumbre", se tenía "gran cuydado y diligencia por sus repartimientos que los trauajos fuesen yguales" (p. 434). Estas descripciones siguen un orden del discurso que atiende a los primeros memoriales y relaciones más arriba analizados, al alabar la justicia incaica y su ponderada exigencia en virtud del mantenimiento de la salud de los naturales.

El licenciado Matienzo había aconsejado, en agosto de 1567, cual declaración de una etnografía autoconsciente, que para el buen gobierno había necesidad "de saber la condición y natural inclinación de los indios", porque mal podía gobernar "el que no conoce la condición de los que han de ser gobernados" (Matienzo 1567, fol. 15v). Las conclusiones del oidor son demoledoras; los indios "no difieren de los animales" (fol. 16r) y son "inclinados a cosas baxas y viles" concluyendo convenientemente que "sacarlos de su natural parece yerro" (fol. 52r). Esta argumentación es elaborada para lanzar a los indios a un determinismo laboral inamovible, caracterizado por oficios técnicos, que no impliquen uso de "razón y prudencia" ya que esta "no cabe en sus entendimientos" (fol. 52v). Esta sentencia había sido sostenida por el licenciado Polo Ondegardo (1561 y 1571), conocido funcionario virreinal, al diseñar su proyecto político de restitución de instituciones prehispánicas, atendiendo al conocimiento que señaló tener de los indios (praxis colonial) y a la necesidad de revertir el descenso sistemático de mano de obra indígena, intentando asegurar una base tributaria estable. En ambos letrados, la condición 
natural/colonial de los indios es presentada como fija e inmutable (Lamana 2012; Morong 2016). En ambos funcionarios, explícita o implícitamente, la restitución de instituciones incaicas será condición sine qua non para la sujeción efectiva de los naturales (Lamana 2012, Morong y Brangier 2019)

La necesidad de los españoles de "conocer" para asegurar gobernabilidad, no era nueva. Para el cuarto virrey, mejor enterados que los españoles "los yngas señores de ellos touieron mas delante de los ojos conociendo la condición de los yndios que heran poco amigos de trabajar quedar orden como la dieron y proueyeron para que no touiesen ociosidad ni fuesen holgazanes", compeliéndolos continuamente y sistemáticamente que laboraran "a hefecto que no andouiesen ny estouiesen ociosos" (Levillier 1921, tomo I: 439-440). La eficacia de este control -en palabras del virrey- radicaba, al igual que el memorial de 1539-1541 y la relación de La Bandera (1557), en la organización decimal de autoridades directas a distintas escalas de poder. Los españoles asombrados no dejaron de admirar el hecho de que hasta para cada cinco indios había una autoridad directa.

Asombrado por el nivel de exigencia laboral y compelido a justificar una tiranía, el oidor de Charcas finalmente sentenciaba que los incas eran capaces de movilizar a los indios para hacer acequias y calzadas insignes "mayores que las que hicieron los romanos y hacer en sierras y cuestas muy altas y llenas de piedras y peñas, andenes de piedra, para que pudiesen sembrar en ellos [...] cosa increible a los que no lo han visto". Esta descripción-que implica una permanente paradoja- le fue conveniente para sostener, finalmente, que la política incaica estaba minuciosamente diseñada para "nos le dexar un punto ociosos" (Matienzo 1567, fol. 10r; Morong y Brangier 2019: 19). Debemos recordar que para los peninsulares la relación entre ocio y trabajo fue considerada de suma importancia, constituyendo un objeto de vigilancia que implicaba prácticas punitivas para su corrección. La erradicación sistemática de esta calidad laboral de los sujetos coloniales (indios, mestizos, negros) era entendida como la aplicación del buen gobierno, ya que el trabajo, su antónimo, era representado como una virtud y un orden natural en los seres humanos, en el sentido de que cada sujeto posee un oficio que le corresponde, dando un sentido útil a su vida (Araya 1999: 13-17).

Siguiendo en esta clave analítica, encontramos una referencia directa al inca en una provisión real entregada a Íñigo Ortiz de Zúñiga por el secretario Diego Muñoz Ternero en Lima, en diciembre de 1561, dando las instrucciones y protocolos para la famosa visita a los Chupaichus en la provincia de León de Huánuco. Este texto -inserto en un expediente abultado, consistente en peticiones, cartas, instrucciones y provisiones que formalizan las instrucciones reales de Felipe II para el desarrollo y ejecución de aquella- señala firmemente la obligación moral de la monarquía "que a esta causa tenemos de mirar por nuestros súbditos y naturales bien y beneficio de ellos y a mantenerlos en justicia y quietud paz sosiego" (Ortiz de Zúñiga 1967 [1562]: 10). Dentro de las soluciones asumidas que implican la consideración mayúscula de reducir a los indios a pueblos para "civilizarlos" y evangelizar sus prácticas, para "dar asiento en la vida y estado de los dichos naturales" (p. 9) está la erradicación del ocio y la normalización del trabajo moderado (cuestión largamente exigida por clérigos dominicos y procuradores de indios desde 1540) (Pérez Fernández 1988). Lo importante de la cita que reproducimos es claramente la referencia al inca como una estructura de poder preocupada de la "salud" de los tributarios, elemento posible al controlar la vagancia;

\footnotetext{
"Tenemos entendido el cuidado que sus yngas antiguos tuvieron de que no estuviesen ociosos porque conocían el daño y perjuicio que era para su salud remedio y aumento allende la policía y bien público que resulta de que no están ociosos y trabajen moderadamente" (Ortiz de Zúñiga 1967 [1572]: 9-10).
}

La naturaleza de la recomendación hecha al visitador, hombre de "de ciencia y experiencia", es informarse de la capacidad de la organización local incaica y ponderar la exigencia laboral para adecuar su factura a las necesidades del régimen colonial. Las autoridades en esta instrucción, rubricada también por los comisarios de la perpetuidad y el Conde de Nieva, concluyen con una asignación identitaria común para los indios hacia 1561, "tenemos cierto que la ociosidad en ellos es la mayor parte de su perdición y poca vida según lo que en estas partes de muchos días atrás se tiene por experiencia y entendido" (p. 9-10). Incluso, el Conde de Nieva en otra carta dirigida a Felipe II, reitera de forma pesimista la naturaleza inherente 
de los indios advirtiendo "que no ay que pensar en creer que de su voluntad han de yr a trauajar porque ellos todos naturalmente son holgazanes y a trueque de no trabajar se dexaran morir de hambre" (Levillier 1921, tomo I: 529). Más aún, la condición de vagancia y la borrachera denunciadas han enfermado a los indios y "esta ha sido la causa de que se ayan menoscabado después que el ynga los señoreo de tal manera que faltan las dos partes dellos" (p. 512-513). Estas conclusiones irán definiendo las características sociológicas de las comunidades andinas bajo el poder de los Austrias, fijando en la escritura una imposición estereotípica de larga duración asociada a la "indianidad" (Bhabha 2002: 92), funcional a las crecientes exigencias tributarias y a su legitimidad axiológica ( Lamana 2012).

\section{Letrados, indios, el gobierno colonial y la restitución del inca}

Al constatar que los incas erradicaron el ocio e impusieron sujeción irrestricta, las autoridades virreinales, letrados y clérigos, a partir de 1560 , cada vez con mayor información a disposición, insistieron y concluyeron taxativamente "en quanto se pudiere bolvellos a las leyes y orden que los yngas tenian para governallos" sobre todo para "quitalles la ociosidad y que trauajen continuo moderadamente" (Levillier 1921, tomo I: 443). Esta conclusión de orden gubernamental fue compartida y asumida por la autoridad colonial de una y otra parte. En sus famosos informes de 1561 y 1571, Polo Ondegardo, más allá de una supuesta simpatía por los indígenas -lo que ha conducido a perfilar erróneamente a un "pro-indigenista" (González Pujana 1977-1981: 109-123)-, recomendaba la continuidad de las prácticas político-administrativas prehispánicas en la Colonia. Como advierte lúcidamente Gonzalo Lamana (2012: 54-55), bajo esta sugerencia restitutiva no existiría un imperativo moral sino "una observación pragmática: la caida de la población y el tributo indígena en los Andes" (p. 55). Polo observará esta caída como consecuencia de las políticas erróneas del colonialismo español al entender que los incas habían construido un corpus normativo necesario y bueno para los naturales. A propósito de su informe de 1571 se lamentaba sosteniendo que "me parece se puede afirmar que hicieron mas daño los españoles en solo cuatro años que el Inca en cuatrocientos" (Polo Ondegardo 2012 [1571]: $55)^{14}$. El daño observado -en términos de descenso demográfico- no aludía a enfermedades o pestes traídas por los conquistadores, sino a la falta de policía, al libertinaje y a los vicios de los indios, producto del ejercicio de su "libertad" colonial y a la ausencia de precisos dispositivos de vigilancia (los naturales, a fin de cuentas, no conocían otra forma de sujeción, no precisaban de decisiones económicas individuales). Según Lamana (2012: 57), el reconocimiento de la condición colonial de los naturales por parte del licenciado (etnografía) le permite razonar sobre la restitución del inca, elogiando sus prácticas gubernamentales orientadas a mantener el trabajo forzado de aquellos, para mantenerlos ocupados a toda costa.

La lógica del pensamiento colonialista supone en los ejemplos de Matienzo y Ondegardo, una explicación ontológica que intenta, utilizando la referencia al inca, otorgar a los indios una identidad estable y esencial, largamente conocida por sus antiguas autoridades, de allí la eficacia de sus prácticas punitivas, sustentadas en la habituación y adecuación milenaria a sistemas políticamente necesarios.

En 1563, y siguiendo las instrucciones de una cédula real de 1553, el licenciado Hernando de Santillán ${ }^{15}$ estando en España, remitía a los oficiales de la Corona su conocida "Relación del origen, descendencia, política y gobierno de los incas" (Santillán 1968 [1563]). Probablemente, constituye la primera relación oficial extensa escrita por un letrado destinada a alabar el gobierno del inca (por ello quizás fue erróneamente signada de crónica) (Estebe Barba 1968). Se sabe que las referencias para escribir su relación las tomó de la relación de Cristóbal de Castro y Diego Ortega Morejón efectuada en 1558 al valle de Chincha, en la costa centro sur del Perú (Sánchez Concha 1996: 291). Como anota Sánchez-Concha (1996: 289) la relación "es fruto de sus observaciones sobre la problemática colonial y de su formación ius naturalista" al concebir el cuerpo de República como una comunidad perfecta basada en una concepción escolástica del mundo. Dicho orden, organizado primariamente por Dios -y por ello perfecto-, puede lograrse si se procura el bien común "cuya manifestación tangible es el "Buen gobierno" (p. 289). Claramente, por su experiencia de letrado y magistrado, estaba facultado para asesorar a la Corona en materia legislativa y a establecer, política y jurídicamente, los elementos que aseguraban el buen gobierno. Sus observaciones y disquisiciones teóricas en el campo del derecho 
natural le permitirán sostener que los incas encarnan las prácticas orientadas al bien común.

A diferencia de las pretensiones de Matienzo e incluso de Polo Ondegardo, sostiene que los incas son el ejemplo máximo del cuerpo de República al promover el bien común (Sánchez-Concha 1996: 289). No existe en su relación nominación alguna al inca como tirano. Al contrario, su sistema político es definido como el "más general y más pulítico y ordenado que ninguno que haya en aquella tierra que haya memoria" (Santillán 1968 [1563]: 104). El leitmotiv de la relación es presentado como lo que "conviene entenderse para que en el gobierno de aquella tierra haya estabilidad" (p. 100). Dentro de las materias específicas del gobierno de los incas, que incluyen tributo, sucesión política, matrimonio, tipos de autoridades, entre otros, señala que a pesar de que los cusqueños "no tuvieron leyes escritas" todos guardaban este orden gubernamental destinado a erradicar el ocio como el "vicio mas castigado" (Santillán 1968 [1563]: 107). A nuestro juicio el licenciado argumenta, al igual que los casos anteriores, en la necesidad del inca dada la naturaleza de los indios:

"es de saber que de su natural los indios de aquellas provincias son por la mayor parte inclinados a la ociosidad y vicios de la carne y glotonería, especialmente en el beber demasiado; por ser gente desta cualidad, les cuadró bien el gobierno que los ingas les pusieron, por el cual casi en ninguna cosa los dejaban libertad" (Santillán 1968 [1563]: 120).

A pesar de que el licenciado aboga por la libertad tutelada de los indios, el ocio crónico y atávico de aquellos impide que critique un sistema de corte autoritario que ha negado la voluntad de sus sujetados. Al describir al tocuirico, mencionado más arriba, argumenta en la eficiencia punitiva de esta autoridad local -comparado incluso con un visitador cristiano- sugiriendo que para remediar lo que "fuese errado, lo cual es llegado al gobierno $\mathrm{y}$ orden de los ingas que para aquella gente es la mas conveniente que otra ninguna" (p. 120), más que el gobierno peninsular. Al desaparecer el tocuirico, que los propios alcaldes de indios alababan al compararlo con el corregidor (AGI, Lima 121, fol. 47r), la disipación y falta de orden favorecieron la pérdida de "aquella sencillez y rectitud que en tiempo eran gobernados por los incas" (p. 109). Del mismo modo, Juan de Matienzo en 1567 formulaba un cuidadoso plan gubernamental en el que, por medio de funciones específicas, se proponía su reinstalación en el contexto de la reducción de pueblos a indios (Morong y Brangier 2019: 19-22).

En 1564 asumía como gobernador interino, en ausencia de virrey, el presidente de la Audiencia de Lima, licenciado Lópe García de Castro. Su impresión del Perú fue determinante "halle la tierra tan perdida y la gente tan descontenta" (Levillier 1921, tomo III: 31-32). Su observación de las instituciones incaicas se vio intervenida con los problemas que debió enfrentar al querer pacificar a los incas de Vilcabamba, en específico con Sairy Tupac y su hermano Titu Cusi Yupanqui entre 1565 y 1568 (Levillier 1921, tomo III: 295). Su experiencia en terreno lo llevó a afirmar que "Quanto mas boy mirando las cosas de esta tierra tanto mas boy sintiendo quan necesario es rremediar el mal gobierno pasado ansi en lo espiritual como en lo temporal" (Levillier 1921, tomo III: 78). Su proposición, siguiendo la línea argumentativa que venimos desarrollando, fue que "era uien que estos naturales tubiesen el gobierno que guaynacaba les abia puesto" (AGI, Lima 121, fol. 5r) ${ }^{16}$. Sus disposiciones tributarias debían seguir "la orden que el ynga tenía que era muy conforme a derecho y razón" (Levillier 1921, Tomo III: 125). Con el gobierno del licenciado García de Castro (1564-1569) quedaba establecido un largo precedente discursivo, orientado insistentemente a elogiar el buen gobierno incaico y la posiblidad de recuperar parte de su policía sociopolítica. Cuando Francisco de Toledo arribó al Perú en 1569 por casi cuarenta años, los españoles venían insistiendo en la necesidad de observar las leyes del inca y habían sugerido recuperar algunas de sus instituciones. Las recomendaciones del Conde de Nieva ya habían sido decidoras; "no es bien mudalles la orden que se les a quedado sino buscar y tornar a cobrar alguna parte de ellas si se ha perdido y tornalla a yntroducir asi en la orden y cuidado que auia sobre ellos". Esta antigua orden había sido dada "para que no muriesen ni enfermasen" (Levillier 1921, Tomo I: 444).

\section{A modo de cierre}

Si atendemos prolijamente a este corpus fragmentario que hemos constituido como objeto de análisis y que hemos revisado aquí, podemos ponderar el contenido de los documentos en un 
ámbito de necesidad gubernamental perentoria; la estabilidad de la política colonial, la disposición de la mano de obra nativa y el aumento del erario real (Stern 1986; Lohmann 1966). A pesar de que el estudio de la política virreinal -en virtud de adecuar los sistemas de poder prehispánicos a la maquinaria colonial- ha ostentado larga data (y la cantidad de referencias son innumerables), nos parece que poco se ha documentado -salvo casos específicos (Lohmann 1957; Mumford 2012)- respecto de una práctica escritural sistemática (en documentación oficial) orientada a imputar a los incas prácticas de buen gobierno, sustentadas en distintos mecanismos e instituciones de poder. Mumford señala (2011: 48) que algunos elementos de la tiranía coincidían con técnicas gubernamentales observadas por los españoles como propias de los incas y necesarias para gobernar a las poblaciones andinas: "el control social y la vigilancia, la igualdad y la atomización de los súbditos, así como proyectos de construcción pública que mantenían a la gente trabajando permanentemente e ingeniería social que conducía a desplazamientos a gran escala de la población" (p. 48). Estas observaciones realizadas antes de la intervención toledana, en un universo heterogéneo de actores con intereses diversos, van a ir formalizando progresivamente un objeto de discurso -el inca y los indios- con fines instrumentales en la lógica de la necesidad de asentamiento y buen gobierno y del control cada vez más urgente de mano de obra indígena ante la coyuntura económica y la expansión de la economía extractiva. La documentación analizada permite especular que esta descripción de los gobernantes cusqueños vino aparejada con la descripción de inferioridad atávica de los indios, es decir, la existencia colonial de los indios, de diversas provincias y latitudes, implicó la valoración de un régimen cruel y estricto pero necesario. Sabemos que la "indianidad" y sus atributos fue una construcción colonial para asegurar y legitimar un proyecto político de dominio de gran envergadura, como lo han mostrado diversas investigaciones.

Esta suerte de legitimidad política, a base de constatar empíricamente un modelo sui generis de orden y policía social, se sostuvo en a lo menos dos descripciones correlacionadas e insistentes: en primer lugar, la efectividad de la organización política incaica en términos de que estos habían impuesto con un orden social perfectamente encuadrado en las necesidades y "naturaleza" del pueblo andino. Es decir, habían manejado un sistema fiscal tan preciso, y a la vez tan flexible, que podía tomar en cuenta las condiciones cambiantes de cada comunidad, en cada región, de un año a otro (Platt 2010:49). Esta capacidad gubernamental, reconocida en cronistas, clérigos y funcionarios, fue deducida por medio de la observación in situ para sostener que una estructura de poder tan eficaz fue producto de una combinación de autoridad y conocimiento estatal de la alteridad (Mumford 2012).

En este sentido, se hace necesario recordar y asumir la premisa, a contrapelo de una historiografía que reconoció en la Corona un estado centralizado y altamente coactivo, que el poder colonial en los territorios americanos -sobre todo en Perú- estuvo provisto de unos aparatos de dominio sumamente precarios (Garriga, 2006: 73) y que los intentos de pacificación y dominio pasaron necesariamente por los sutiles pero eficientes mecanismos de negociación con las autoridades étnicas, únicas capaces de articular la inestimable y escurridiza fuerza laboral de los naturales y asegurar cierta estabilidad política (Penry 2019; Zuloaga 2012, Morrone 2016). Esta ponderación, sobre la experiencia in situ y la aguda observación de las "realidades locales", otorgó un sentido práctico a las labores cotidianas de gobierno, iterpelando a ratos la normatividad metropolitana.

Para algunos letrados, oficiales y clérigos el régimen colonial, portador de libertad y civilidad para los indios, comenzaba a generar visibles consecuencias; disipación, borrachera, ocio, holgazanería, amancebamiento, traición y, sobre todo, improductividad. La descripción permanente en estos informes, alterna la necesidad de tutelaje y paternalismo frente a una descarnada descripción de salvajismo, interdicción e inferioridad inherente. Los indios padecían pobreza y abusos a causa del servicio personal, de las tasaciones excesivas, del transporte de cargas inmoderadas y del traslado de un "temple" a otro al que se les sometía (Pérez Fernández 1988: 269-270), pero también se emborrachaban y se habían vuelto vagabundos, al igual que muchos españoles y mestizos. La experiencia y la sistemática observación in situ les haría comprender que durante el gobierno incaico los indios, a pesar de ser subyugados y compelidos al trabajo obligatorio, estaban sanos y en aumento demográfico, lejanos de cualquier "vicio o maña" en un estricto y positivo orden biopolítico.

De tal manera, no debe dejarse de lado el análisis a las estrategias pragmáticas de toda racionalidad política, que más allá de cualquier interpelación 
ideológica, secular o religiosa, reconocieron dentro de sus propios límites un compromiso respecto de la adecuación de prácticas de poder prehispánicas en el periodo colonial. En este sentido, intentamos pensar la dominación colonial bajo la lógica de una "hegemonía no absoluta". Con todo, hemos querido poner en evidencia los derroteros de la política imperial, los usos de la praxis política-jurisdiccional en la solución de aquellos y la legitimidad progresivamente adquirida por la información levantada empíricamente referida a gobierno y gobernanza.

\section{Agradecimientos}

El presente artículo se enmarca en el desarrollo y ejecución del proyecto Fondecyt de iniciación 11180045 "Letrados, etnografía y proyecto de sujeción colonial. Los incas y los indios en la pluma de la burocracia virreinal, Perú 1557-1570”. Agradecemos a la Agencia Nacional de Investigación y Desarrollo (ANID-Chile) por el financiamiento de tres años a este proyecto. Agradecemos también el trabajo de transcripción paleográfica, fichaje y fijación de descriptores de los ayudantes del proyecto, Sebastián Salgado y Rita Poblete, estudiantes de Pedagogía en Historia y Geografía, Facultad de Educación, UBO. Finalmente, esta contribución, incluida en el presente dossier "Cultura gubernamental y jurídica, actores políticos y redes de poder en el centro sur andino, S.XVI-XVII" se elaboró en el marco de colaboración interinstitucional entre el Centro de Estudios Históricos (CEH) de la Universidad Bernardo O'Higgins y la Facultad de Filosofía y Letras, Instituto de Historia Argentina y Americana Dr. Emilio Ravignani, de la Universidad de Buenos Aires.

\section{Referencias Citadas}

\section{Fuentes primarias}

-Archivo General de Indias (AGI)

Lima 120.

Lima 121.

-New York Public Library (NYPL)

Obadian Rich Collection, Ms 74.

-Biblioteca Nacional de España (BNE)

Ms 2010.

\section{Fuentes éditas impresas}

Anónimo

2013 [1539-1541] "Carta sobre el gobierno, las costumbres y los antiguos ritos del Perú”, transcripción paleográfica y edición crítica por Margarita Gentile, "Un memorial pretoledano sobre el Tahuantinsuyu: relectura en 2012", Anuario Jurídico y Económico Escurialense, XLVI: 497-524.

La Bandera, Damián de

1881 [1557] "Relación general de la disposición y calidad de la provincia de Guamanga, llamada San Joan de la Frontera y de la vivienda y costumbres de los naturales della" en Relaciones Geográficas de Indias, Tomo I, pp. 96-104. Tipografia de Manuel Hernández, Madrid.

Matienzo, Juan de

1967 [1567] Gobierno del Perú. IFEA, Lima-Paris.

Segovia, Bartolomé de

2019 [1552-1556] La relación Conquista y población del Pirú, fundación de algunos pueblos, Pilar Roselló (ed). PUCP, Lima.

Ondegardo, Polo.

2012 [1561] "Informe del licenciado Juan Polo Ondegardo al licenciado Briviesca de Muñatones sobre la perpetuidad de las encomiendas en el Perú", en Gonzalo Lamana (ed.), Pensamiento colonial crítico. Textos y actos de Polo Ondegardo, pp. 139-204. Instituto Francés de Estudios Andinoos y Centro Bartolomé de Las Casas, Lima/Cuzco. Ondegardo, Polo

2012 [1571] "Las razones que movieron a sacar esta relación y notable daño que resulta de no guardar a estos indios sus fueros" en Gonzalo Lamana (ed.), Pensamiento colonial crítico. Textos y actos de Polo Ondegardo, pp. 139-204. Instituto Francés de Estudios Andinoos y Centro Bartolomé de Las Casas, Lima/Cuzco.

Ortiz de Zúñiga, Íñigo

1967 [1562] Visita de la provincia de León de Huanuco, Tomo I, John Murra (ed.). Universidad Hermilio Valdizan, Lima.

Santillán, Hernando de

1968 [1563] Relación del origen, descendencia, política y gobierno de los Incas, F. Esteve Barba (ed.), Crónicas peruanas de interés indígena, Vol. 209, BAE, pp. 97-150. Ed. Atlas, Madrid.

\section{Fuentes secundarias}

Araya, A.

1999 Ociosos, vagabundos y malentretenidos en Chile colonial, Santiago. LOM/DIBAM, Santiago.

Assadourian, C.

1982 El Sistema de la Economía Colonial. Mercado Interno, Regiones y Espacio Económico. IEP, Lima.

Assadourian, C.

1994 Transiciones hacia el sistema colonial andino. IEPCOLMEX, Lima-México.

Barrera-Osorio, A.

2006 Experiencing Nature. The Spanish American Empire and the Early Scientific Revolution. University of Texas Press, Austin. 
Betancor, O.

2017 The Matter of Empire. Metaphysics and Mining in Colonial Peru. University of Pittsburgh Press, Pittsburgh.

Bhabha, $\mathrm{H}$.

2002 [1994] El lugar del la Cultura. Ed. Manantial, Buenos Aires.

Brading, D.

1991 Orbe Indiano. FCE, México.

Brendecke, A.

2012. Imperio e información. Funciones del saber en el dominio colonial español. Madrid/ Frankfurt, Iberoamericana-Vervuert.

Cunill, C.

2011 "El indio miserable: nacimiento de la teoría legal en la América colonial del siglo XVI", Cuadernos inter.c.a.mbio, Vol. 8 (9): 229-248.

Clifford, J.

2001 Dilemas de la cultura. Antropología, literatura y Arte en la perspectiva postmoderna. Gedisa, Barcelona.

Domínguez, Nicanor.

2008 "Betanzos y los Quipucamayos en la época de Vaca de Castro (Cuzco, 1543)", Revista Andina 46: 155-192.

Domínguez, N.

2010 El licenciado Polo: ¿fuente del "Discurso sobre la descendencia y gobierno de los ingas" (ms. 1602/16031608)?, Histórica XXXIV(1): 131-144.

Duviols, $\mathrm{P}$

1979 "Datation, paternité et idéologie de la "Declaración de los Quipucamayos a Vaca de Castro" (Discurso de la descendencia y gobierno de los Ingas)". En Les cultures ibériques en devenir. Essais publiés en hommage à la mémoire de Marcel Bataillon (1895-1977), pp. 583-591. Fondation Singer-Polignac, Paris.

Duviols, P.

1982 "Revisionnisme historique et droit colonial au 16éme siécle: le théme de la tyrannie des incas", en Indianité ethnocide indigenisme en Amérique Latine, pp. 11-22. CNRS, París.

Earle, R.

2012 The Body of the Conquistador: Food, Race and the Colonial Experience in Spanish America, 1492-1700. Cambridge University Press, New York.

Esteve Barba, F.

1968 "Estudio preliminar". En Crónicas peruanas de interés indígena, Biblioteca de Autores Españoles, Vol. 209. Ed. Atlas, Madrid.

Foucault. M.

1979 La arquelogía del saber. Siglo XXI editores, México.

Garriga, C.

2006 "Sobre el gobierno de la justicia en indias (siglos XVIXVII)", Revista de Historia del Derecho 34: 67-160.

Gaudin, G.

2017 El imperio de papel de Juan Díez de la Calle. Pensary gobernar el Nuevo Mundo en el siglo XVII. FCE, México.

Gentile, $M$.

2013 "Un memorial pretoledano sobre el Tahuantinsuyu: relectura en 2012", Anuario Jurídico y Económico Escurialense, XLVI: 497-524.

Gibson, C.

1948 The Inca Concept of Sovereignty and the Spanish Administration in Perú. The University of Texas Press, Austin.
Góngora, M.

1951 El Estado en el derecho indiano. Época de fundación 1492-1570. Instituto de investigaciones histórico-culturales/ Universidad de Chile, Santiago.

González Pujana, L.

1977-1981 "El indigenismo de Polo de Ondegardo", Boletín del Instituto Riva-Agüero 11: 109-123.

Hall, S.

2003 “Introducción; ¿Quién necesita identidad?” en Cuestiones de identidad cultural. Amorrurtu, Buenos Aires.

Hanke, L. (editor).

1978-1980 Los virreyes españoles en América durante el gobierno de la Casa de Austria: Perú, Vol. I. Ed. Atlas, Madrid.

Honores, R.

2004 "El licenciado Polo y su informe al licenciado Briviesca de Muñatones (1561)". En Ignacio Arellano y Frmín del Pino (eds.), Lecturas y ediciones de crónicas de Indias. Una propuesta interdisciplinaria. Iberoamericana/Vervuert, Madrid/Frankfurt.

Julien, C.

2016a "Relación breve de la religión y gobierno de los Ingas" (ca. 1551). En Joanne Pillsbury (ed.), Fuentes documentales para los estudios andinos, Vol. III, pp. 1707-1709. PUCP, Lima.

Julien, C.

2016b "Relación de las muchas cosas acaecidas en el Perú" (ca. 1552). En En Joanne Pillsbury (ed.), Fuentes documentales para los estudios andinos, Vol. III, pp. 1717-1720. PUCP, Lima.

Lamana, G.

2012 "Pensamiento colonial crítico. Polo Ondegardo, Los Andes, y los Estudios Andinos". En Gonzálo Lamana (ed.), Pensamiento colonial crítico. Textos y actos de Polo Ondegardo, pp. 49-87. IFEA/CBC, Lima.

Levillier, R.

1921 Gobernantes del Perú. Cartas y papales, siglo XVI. Colección de Publicaciones Históricas de la Biblioteca del Congreso Argentino, Tomo I. Sucesores de Rivadeneira, Madrid.

Levillier, R.

1921 Gobernantes del Perú. Cartas y papales, siglo XVI. Colección de Publicaciones Históricas de la Biblioteca del Congreso Argentino, Tomo III. Sucesores de Rivadeneira, Madrid.

Lohmann, G.

1957 El Corregidor de indios en el Perú bajo los Austrias. Ediciones Cultura Hispánica, Madrid.

Lohmann, G.

1966 Juan de Matienzo, autor del Gobierno del Perú (su personalidad y su obra), Escuela de Estudios HispanoAmericanos, Sevilla.

MacCormack, S.

2007 On the Wings of Time: Rome, The Incas, Spain, and Peru, Princeton University Press, Princeton.

Martínez, J.L.

1995 Autoridades en los Andes. Los atributos del señor. PUCP, Lima.

Martínez, J.L.

2011 Gente de la tierra de guerra: los lipes en las tradiciones andinas y el imaginario colonial. PUCP/DIBAM, Lima. 
Millones, L.

1998 "De Señores Naturales a Tiranos: El concepto politico de los incas y sus cronistas en el siglo XVI", Latin American Literary Review, Vol. 26 (52): 72-99.

Morong, $\mathrm{G}$.

2014 "Dispositivos de sujeción colonial; el uso de la condición melancólica en dos textos hispanos, Perú 1567/1616", Revista de Humanidades, 30: 167-193.

Morong, G.

2016 Saberes hegemónicos y dominio colonial. Los indios en el Gobierno del Perú de Juan de Matienzo (1567). Prohistoria, Rosario.

Morong, G. y Brangier, V.

2019 "Los Incas como ejemplo de sujeción. El Gobierno del Perú y la escritura etnográfica del oidor de Charcas, Juan de Matienzo (1567)", Estudios Atacameños, 61: 5-26.

Morrone.

2013 "Estrategias estatales y liderazgo étnico en el corregimiento de Pacajes (1538-1620)". En Ana María Presta (ed.) Aportes multidisciplinarios al estudio de los colectivos étnicos Surandinos, “Qaraqara- Charca; Reflexiones a tres años después. Plural/Ifea, La Paz-Lima.

Mumford, J.

2011 "Francisco de Toledo, admirador y émulo de la "tiranía" inca", His- tórica, Vol. XXXV (2): 47-65.

Mumford, J.

2012 Vertical Empire; The General Resettlement of Indians in the Colonial Andes. Duke University Press, Duke.

Ossio, J.

2008 En busca del orden perdido. La idea de la historia en Felipe Guamán Poma de Ayala. PUCP, Lima.

Pagden. A.

1988 La caída del hombre natural. Alianza editorial, Madrid.

Parra, R.

2015 La tiranía del Inca. El Inca Garcilaso y la escritura política en el Perú colonial (1568-1617). Ediciones Copé, Lima.

Pease, F.

1992 Curacas, reciprocidad y riqueza. PUCP, Lima.

Pease, F.

1995 Las crónicas y los Andes. FCE, Lima-México.

Pérez Fernández, I.

1988 Bartolomé de Las Casas en el Perú: 1531-1573. Centro de Estudios Rurales Bartolomé de Las Casas, Cuzco.

Penry, E.

2019 The people are king. The Making of an Indigenous Andean Politics. Oxford University Press, New York.

Platt, T.

2010 John V. Murra, Actor (Odessa 1916-Ithaca, NY 2006). La retórica de la exageración, Chungara 42 (1): 49-57.
Presta, A.

2014 Encomienda, familia y negocios en Charcas colonial. Los encomenderos de la Plata, 1550-1600. ABNB, Sucre.

Rostworowski, M.

1983 Estructuras andinas del poder. Ideología política y religiosa. IEP, Lima.

Rowe, J.

1966 "Un Memorial del Gobierno de los Incas del Año 1551", Revista Peruana de Cultura 9-10: 26-39.

Salomon, F.

1997 Los Yumbos, Niguas y Tsatchila o "Colorados" durante la colonia española: Etnohistoria del Noroccidente de Pichincha, Ecuador. Ed. Abya Yala, Quito.

Sánchez-Concha, R.

1996 "El licenciado Hernando de Santillán y sus observaciones en torno de las formas tiránicas de los curacas", Histórica vol. XX (2): 285-302.

Sarabia Viejo. M.

1978 Don Luis de Velasco, virrey de Nueva España15501564. Escuela de Estudios Hispano-Americanos, Sevilla.

Spalding, K.

1974 De indio a campesino: cambios en la estructura social del Perú colonial, IEP, Lima.

Solodkow, D.

2014 Etnógrafos Coloniales. Alteridad y escritura en la Conquista de América (siglo XVI). Iberoamericana-Vervuert, Madrid/Frankfurt.

Stern, S.

1986 [1982] Los pueblos indígenas del Perú y el desafío de la conquista española, Huamanga hasta 1640. Alianza Editorial, Madrid.

Trimborn, $\mathrm{H}$.

1935 "Unsere älteste ethnographische Quelle über das Inkareich", Zeitschrift für Ethnologie 66: 402-416.

Wedin, A.

1966 El concepto de lo incaico y sus fuentes. Studia Histórica Gothoburgencia VII, Uppsala.

Zuidema, $\mathrm{T}$.

2008 "El Inca y sus curacas: poliginia real y construcción del poder", Bulletin de l'Institut français d'études andines [En línea], 37 (1), Publicado el 01 octubre 2008, consultado el 24 junio 2020. URL: http://journals.openedition.org/ bifea/3284.

Zuloaga.

2012 La conquista negociada, guarangas, autoridades locales e imperio en Huaylas, Perú (1532-1610). IEP/IFEA, Lima.

Zavala, S.

1976 El Servicio personal de los indios en el Perú (extractos del siglo XVI), Tomo I. El Colegio de México, México. 


\section{Notas}

1 La escritura etnográfica contenida en la documentación colonial debe ser entendida también como una formación discursiva (Foucault 1979: 51-64; Solodkow 2014) que englobó géneros ya constituidos (relaciones, cartas, memoriales, etc.), y que posibilitó la emergencia y despliegue de la representación de una identidad cultural o de varias identidades paralelas, acentuando el carácter dinámico y performativo de estas (Hall 2001; Martínez Cereceda 2011). Esta práctica escritural -etnográfica- produciría interpretaciones culturales a partir de una intensa experiencia de investigación in situ, como es el caso específico de relaciones e informaciones. Además, implicaría una estrategia discursiva de autoridad específica (Clifford 2001: 43).

2 Mi traducción del inglés.

3 Incluso el virrey Velasco defendió la supervivencia de las normas indígenas siempre que no fuesen injustas, incluyendo, más tarde, las normas referentes al mantenimiento del juzgado de indios en su recopilación de leyes (Saravia Viejo 1978: 27).

4 Para esta contribución hemos constituido un corpus fragmentario, a saber; Anónimo Carta sobre el gobierno, las costumbres y los antiguos ritos del Perú (1539-1541?); Bartolomé de Segovia, La Relación, Conquista y Población del Pirú, Fundación de algunos pueblos (1552-1556?); Damián de la Bandera, Relación general de la disposición y calidad de la provincia de Guamanga, llamada San Joan de la Frontera y de la vivienda y costumbres de los naturales della (1557); Cartas y papeles enviados al rey por el Virrey Conde de Nieva (1561-1564); Hernándo de Santillan, Relación del origen, descendencia, política y gobierno de los Incas (1563); Cartas y papeles enviados al rey por el licenciado Lope García de Castro (15641569); Juan de Matienzo, Gobierno del Perú (1567); Polo Ondegardo, Informe del licenciado Juan Polo Ondegardo al licenciado Briviesca de Muñatones sobre la perpetuidad de las encomiendas en el Perú (1561), Las razones que movieron a sacar esta relación y notable daño que resulta de no guardar a estos indios sus fueros (1571) y Cartas y expedientes de personas seculares del distrito de la Audiencia de Lima, vistos o resueltos en el Consejo; cartas, peticiones, expedientes e informaciones (1562-1566) (AGI, Lima 120 y 121). Para la referencia completa de estas obras revisar bibliografía final.

5 Orlando Bentancor (2017: 237-254) sostiene que las bases epistémicas de esta clasificación de la alteridad estarían estrechamente vinculadas a un "instrumentalismo metafísico imperial". Este instrumentalismo, fundado en la ley natural, legitimó jurídica y políticamente el trabajo servil de los indios.

6 La información contenida en estas tipologías obedeció a la necesidad imperial de afianzar la posición de dominio en los Andes y aprovechar al máximo los recursos existentes, además de representar muy bien las intenciones y necesidades particulares de sus redactores, en el contexto de la administración peninsular.

7 Entre estos contamos con dos textos conocidos y analizados por la etnohistoria e historia colonial que refieren a los primeros informes sobre los incas, su historia y sus mecanismos de autoridad; por un lado, el polémico Discurso sobre el origen y descendencia de los incas Biblioteca Nacional de España (BNE), Ms. 2010, fols. 44-66v. Este documento fue publicado por primera vez por Marcos Jiménez de la Espada (1892) bajo el título de "Una antigualla peruana". Una segunda versión édita fue publicada por Horacio Urteaga (1921) con el nombre de "Declaración de los quipucamayos a Vaca de Castro" en sus famosas "Informaciones sobre el Antiguo Perú (crónicas de 1533 a 1575) de la Colección de Libros y Documentos referentes a la Historia del Perú. Existen dos ediciones más; una de 1974 y otra del 2004. Esta última apareció junto con la crónica de Juan de Betanzos editada por María del Carmen Martín Rubio. La polémica que envuelve a este documento es la fecha de su redacción, ya que sus referencias son los sucesos de 1541-43 pero su redacción sería de 1608, en manos de fray Antonio Martínez (Duviols 1979, Domínguez Faura 2008). Para una revisión exhaustiva del Discurso y sus derroteros, incluida la polémica por su datación, véase Domínguez Faura (2008 y 2010). El segundo manuscrito temprano constituye una carta anónima llamada "Carta sobre el gobierno, las costumbres y los antiguos ritos del Perú", alojado en la Real Biblioteca del Monasterio, San Lorenzo del Escorial, Códice \&.II.7, 2.4.25, fols. $457.458 \mathrm{v}$. Sus ediciones modernas (Trimborn 1935: 402-416; Rowe 1966: 26-39; Gentile 2013: $497-$ 524) expresan la importancia asignada en función de ser asumida como la fuente disponible más temprana sobre los incas. Los autores de las tres ediciones no precisan acuerdo sobre su fecha, oscilando la eventual redacción entre 1541 y 1551 . Para una exhaustiva revisión heurística y filológica del memorial, ver Gentile (2013).

$8 \quad$ Ver nota 7.

9 M. Gentile (2013: 502) especula que su autor pudo haber sido el clérigo Cristóbal Díaz de los Santos que acompañó Joan Velázquez Altamirano, uno de los futuros encomenderos de Atacama, al valle de Casabindo a bautizar a los indios que estaban de guerra. Por su parte H. Trimborn (1935: 403) conjeturó la posibilidad que fuera Pedro de Quiroga, mientras que Porras Barrenechea (1986: 751) signó la autoría al dean Luis de Morales, activo defensor de los indios en aquella época.

10 Desde 1540 varios religiosos habían denunciado, entre otras cosas, el transporte de cargas a que se sometía a los indios y el traslado de estos de un clima a otro según conveniencias de los encomenderos. Para el obispo de Popayán Juan del Valle, el futuro obispo de Charcas Domingo de Santo Tomás, para Jerónimo de Loaysa y para letrados como el licenciado Francisco Falcón, esta era la causa determinante del veloz descenso demográfico de los naturales del centro sur andino (Pérez Fernández 1988: 270).

11 El documento original se encuentra alojado en el Archivo General de Indias bajo la signatura Patronato, 28, R. 12.1.1.

12 Según Pilar Rosselló (2019: 16-17) el texto en comento no está firmado ni fechado. Desde su hallazgo en el siglo XVIII ha sido copiado y editado varias veces bajo distintos títulos, atribuido también a varios autores. El contexto de producción de la obra, la sistemática explotación colonial del mundo andino y la desestabilización de la política 
colonial en la década $1550-60$, y la cercanía con los postulados lascasianos, ha llevado a conjeturar que la Relación habría sido escrita por un clérigo que presenció de cerca los hechos de la conquista. Al interior de la discusión sobre su autoría, ha figurado el nombre de Cristóbal de Molina "el almagrista" y su Relación de las cosas acaecidas en el Pirú (Esteve Barba 1968; 97-149). Esta última atribución autoral ha sido descartada en virtud de un cotejo de la escritura de la Relación con otros escritos del almagrista, donde parece haber inconsistencia. La confusión sistemática y el problema de atribución, recientemente zanjada, probablemente se han debido a que ambas figuras acompañaron o se vincularon a Diego de Almagro en su empresa a Chile. Para la autora la relación "constituye un documento valioso, con información no suficientemente valorada y que merece ser reubicada en el contexto de las fuentes coloniales y de la historia colonial peruana" (2019: 48).

13 Cfr. Matienzo, Gobierno del Perú, fols. 15v-17v.

14 Me permito transliterar una frase de Polo Ondegardo ya citada por Lamana (2012: 55).

15 Hernando de Santillán fue oidor de la Audiencia de Lima, teniente de gobernador de Chile y luego presidente de la Audiencia de Quito. Para una revisión exhaustiva de la obra política del licenciado, ver Sánchez-Concha (1996: 285-302).

16 La fecha que entrega Roberto Levillier para esta afirmación del licenciado es incorrecta; señala como fecha $1565 \mathrm{y}$, al cotejar el documento original, la fecha exacta está datada a fines de abril de 1566. 